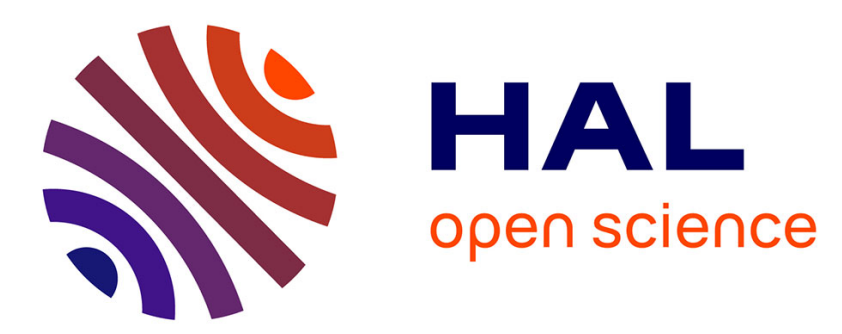

\title{
Seals Based on Magnetic Fluids for High Precision Spindles of Machine Tools
}

Harkaitz Urreta, Gorka Aguirre, Pavel Kuzhir, Luis Norberto López de Lacalle

\section{To cite this version:}

Harkaitz Urreta, Gorka Aguirre, Pavel Kuzhir, Luis Norberto López de Lacalle. Seals Based on Magnetic Fluids for High Precision Spindles of Machine Tools. International Journal of Precision Engineering and Manufacturing, 2018, 19 (4), pp.495-503. hal-01970786

\section{HAL Id: hal-01970786 https://hal.science/hal-01970786}

Submitted on 6 Jan 2019

HAL is a multi-disciplinary open access archive for the deposit and dissemination of scientific research documents, whether they are published or not. The documents may come from teaching and research institutions in France or abroad, or from public or private research centers.
L'archive ouverte pluridisciplinaire HAL, est destinée au dépôt et à la diffusion de documents scientifiques de niveau recherche, publiés ou non, émanant des établissements d'enseignement et de recherche français ou étrangers, des laboratoires publics ou privés. 


\title{
Seals based on magnetic fluids for high precision spindles of machine tools
}

(1)

(1)

\author{
1 IK4-IDEKO, Arriaga 2, E-20870 Elgoibar, Spain
}

* Corresponding author hurreta@ideko.es; Tel: +34943748000 ; Fax: +34943743804

\begin{abstract}
The research work reported in this paper is focused on the use of magnetic fluids as active elements in seals for improving sealing capacity and minimizing friction torque, with application to the spindles of high precision machine tools. The prototype design was optimized following numerical computation of the magnetic field in the rings of the seal. Two magnetic fluids were analysed for their use in the seals: a ferrofluid and magnetorheological fluid. The sealing capacity of the MRF based seals was higher than $45 \mathrm{kPa}$ per ring, but the friction of the seal in the bearing was $8 \mathrm{~N} \cdot \mathrm{m}$, too large for the use in precision spindles of machine tools. The ferrofluid seal achieved sealing capacity around $9 \mathrm{kPa}$ per ring, good enough to be used in the spindles of machine tools, with a friction $0.25 \mathrm{~N} \cdot \mathrm{m}$. The feasibility of using ferrofluids for developing high performance seals for high precision spindles and the validity of the simulation models has been demonstrated experimentally.
\end{abstract}

\section{Keywords}

Magnetic fluids, ferrofluids, magnetorheological fluids, magnetic fluid sealing, machine tool spindle. 


\section{INTRODUCTION}

The introduction is divided in three sections, 1) a brief introduction to classic seals and labyrinths for high precision spindles in machine tools, 2) behavior of magnetic fluids and their technological applications, and 3) seals for spindles and bearing houses 30 based on magnetic fluids.

\subsection{Seals and labyrinths for high precision machine tools}

High precision spindles of machine tools, as used in grinding machines, usually implement hydrostatic bearings in their main shafts (wheelhead, workhead or tailstock)

34 in order to ensure the highest quality and accuracy of the grinded parts, since hydrostatic lubrication provides best performance in terms of positioning resolution, damping capacity and motion smoothness [1]. Hydrostatic lubrication requires handling pressurized oil within the machine, fed through a manifold into the bearing and back into the tank, and the sealing of the whole system is a critical issue in the reliability of 39 the bearings [2].

The sealing of the bearing housing must be ensured whether the shaft is at rest or rotating at nominal velocity, avoiding the contamination of the lubricant oil with the cutting fluid, chips from machining, abrasive micro grains from grinding, and any other potential contaminant within the machine tool. A wide review of available sealing

44 technologies was given by Müller and Nau in their book about the principles and applications of fluid sealings [3].

One of the most active fields in the study of fluid seals is turbomachinery and rotordynamics, focused on energy applications [4]. CFD studies were carried out to analyse the force perturbation in the system, key issue to ensure fluid stability [5], and 
those forces were also studied from the tribology point of view, where the forces are

50 reduced with pattern based surface microtexturing [6].

51 In the particular case of hydrostatic journal bearings lubricated with low viscosity

52 fluids, as in the lubrication of very high speed bearings sealing (i.e. CBN grinding 53 applications), it is very important to avoid leakage in the spindle. An extreme case due 54 to very low viscosity is the water based hydrostatic lubrication, as presented in [7].

Therefore, high sealing capacity and low friction force are the main performance criteria for bearing seals. A solution based on magnetic fluids is proposed in this work.

\subsection{Magnetic fluids, behaviour and applications}

Magnetic fluids are materials whose physical properties can be tuned by external magnetic fields. Two main groups can be distinguished: ferrofluids and magnetorheological fluids, MRF hereinafter. All magnetic fluids are formed by: carrier

61 fluid, additives to improve fluid stability, and magnetic particles. The size of the magnetic particles, nanometric or micrometric, categorize them as ferrofluids or MRF

63 respectively. Ferrofluids are compose by nanometric (5-12nm diameter) particles, and due to their size and energy balance (gravity < particle's thermal energy) the colloidal suspension is stable in time. These particles are usually formed by iron or cobalt oxides, covered with surfactants (like oleic acid) to avoid aggregation and final settling of the particles. The most relevant reference in ferrofluids behaviour is a book by Rosenweig

68 (Rosensweig 1985), while a wide overview of the synthesis, characterization and application of ferrofluids is presented in the compilation book by Odenbach [8].

The MRF are similar to ferrofluids but the magnetic particles are in the range of micrometres, within 1 to $10 \mu \mathrm{m}$, mainly made of carbonyl iron powder (CIP). They are 
72 strongly unstable, settling of the particles is inevitable, but to avoid agglomeration and

73 to have a quick restoration of homogeneous MRF, the fluids include several additives,

74 usually kept confidential by commercial manufacturers.

75 Engineering applications of magnetic fluids range from active dampers, bearings 76 lubrication, hydraulic actuators to sealing of spindles [9]. In this research paper the 77 application to spindle seals will be analysed.

\subsection{Face sealing based on magnetic fluids for machine tool spindles}

Magnetic fluids based seals were presented in the early 1980's where the basic

80 design parameters were established [10], such as the gap, size and the distance between

81 the rings. Simulations of those seals with non-linear models to consider the real magnetization curve were discussed [11]. Looking for a better response in the ferrofluids based seals, the centrifugal force was analysed in the case of high speed systems [12], computing Reynolds equations together with the magnetic pressure to consider high speed effects in the fluid.

A theoretical study of the sealing capacity of large seals was presented, including 87 centrifugal, gravitational and magnetic effect [13]. The main parameters to be considered in the design were identified: Width of the rings, distance between them and

89 the effect of the gap and magnetic fluid volume. Other papers went further in the

90 theoretical study and analysis of ferrofluids based seals with free surface consideration (

91 [14]-[16]) discussing the self-sealing capacity of ferrofluids for applications such as 92 bearings. 
93 The use of MRFs for sealing applications was considered by Vardarajan [17], where

94 the pressurization and the wear generated in the rings by the magnetic fluids with 95 strong yield stress was studied.

96 Finally a deep theoretical and experimental study of ferrofluids based seal was 97 presented in [18], discussing the maximum pressure achieved by the rings and the 98 recovery pressure after the fluid seal was broken, once the maximum pressure was 99 overcome.

100 This research work was focused in the use of magnetic fluid seals for the application 101 of high precision spindles in machine tools. The work was based on the models 102 presented in the literature, two commercial magnetic fluids that were characterized 103 experimentally in the research, and a final construction of a prototype that was used to 104 validate the seal in close to industrial conditions. A section view of a magnetic fluid 105 based seal is described below following the numeration of Figure 1:

106 Semi-shaft: Rotating shaft. Sealing rings (part 2) is assembled in the semi-shaft.

1072 Sealing rings: Ferromagnetic part filled with magnetic fluid. Sealing rings are 108 machined in this part, and magnetic fluid seals are formed in the edges. Different ring 109 edge shapes are studied in the research.

1103 Magnetic poles: Steel made rings to conduct magnetic field from the magnets (part 1114 ) to the seal rings (part 2).

1124 Magnets: Strontium ferrite made permanent magnets

1135 Seal body: Main structure of the seal made in aluminium. Air pressure is achieved 114 into the body, air inlet (orifice 7). 
1156 Assembly cover: Cover ring to assemble the sealing prototype.

1167 Air inlet: Compressed air inlet to the main body. Interior volume of seal body (5) is

117 pressurized with compressed air, introduced by air inlet (7), with sealing capacity given

118 by sealing rings (2).

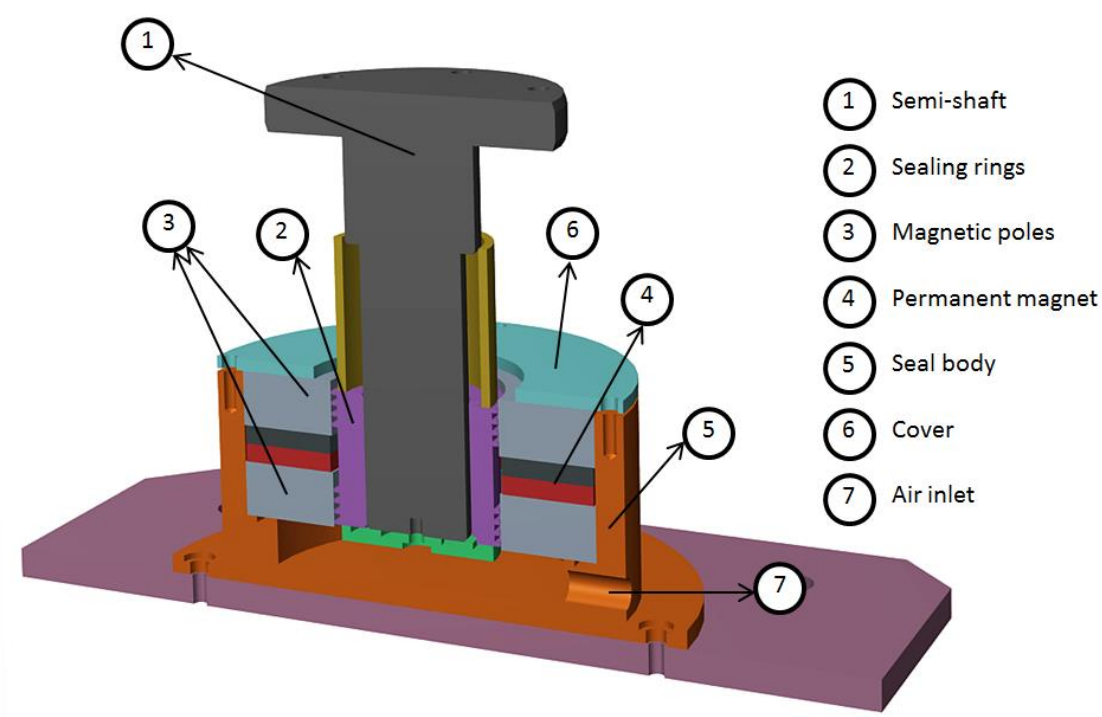

Figure 1 Magnetic fluids sealing, section view with parts description.

119 In Section 2, the experimental characterization of the magnetic fluids used in the

120 research is performed; Section 3 deals with the modelling of the seals; Section 4

121 presents the test bench and the prototype for experimental validation; Section 5

122 summarizes the results and finally in Section 6 the main conclusions are outlined. 
126 Most magnetic fluid based seals found in the literature use ferrofluids, but there are

127 also some solutions based on MRF. In order to analyse both alternatives, the following

128 commercial magnetic fluids were used in this research work: a ferrofluid from

129 FERROTEC® APG s10n and a magnetorheological fluid from LORD® Corp. model

130 MRF 122-2ED. Data given by manufacturers are usually approximate values, both for

131 magnetic and rheological behaviour, and therefore a detailed characterization of these

132 fluids was performed, looking at the magnetic response and the rheological properties

133 under the magnetic field and the temperature. The characterization of those fluids was

134 essential to have an accurate computation of fluids magnetization and sealing capacity

135 of the rings, as it is presented in section 3.

136 The magnetic characterization was performed with a Magnet-Physik Permagraph L

137 magnetometer and the electromagnet EP-3, from which the magnetic field strength, flux

138 density (Figure 2), and magnetic fluid permeability were obtained (Figure 3). The

139 magnetorheological characterization was carried out with a Thermo HAAKE

140 RheoStress RS150, with a magnetic module and a thermally controlled plate. 


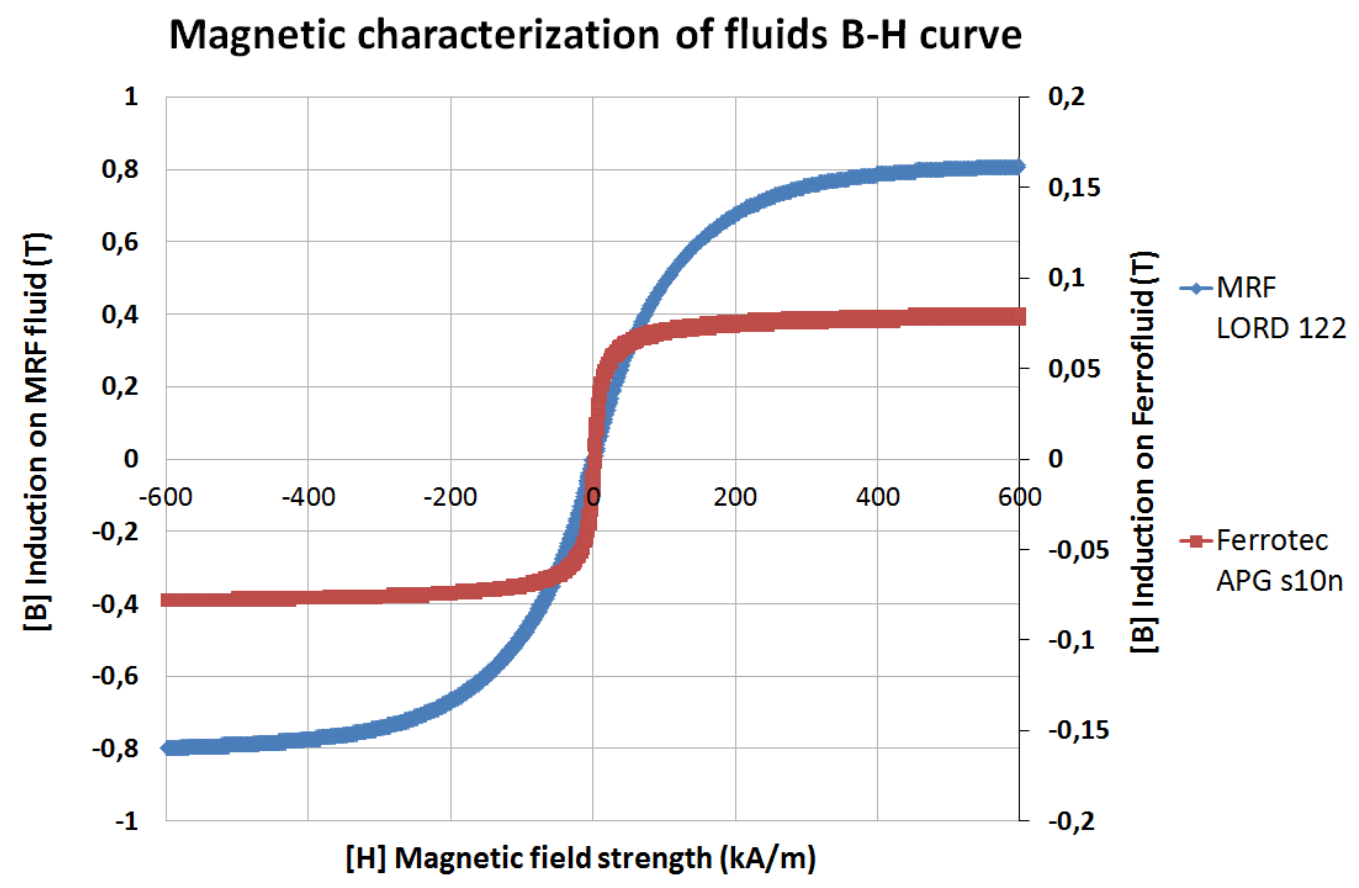

Figure 2 Magnetic characterization of the magnetic fluids: flux density and magnetic field strength.

Magnetic characterization of fluids - Permeability

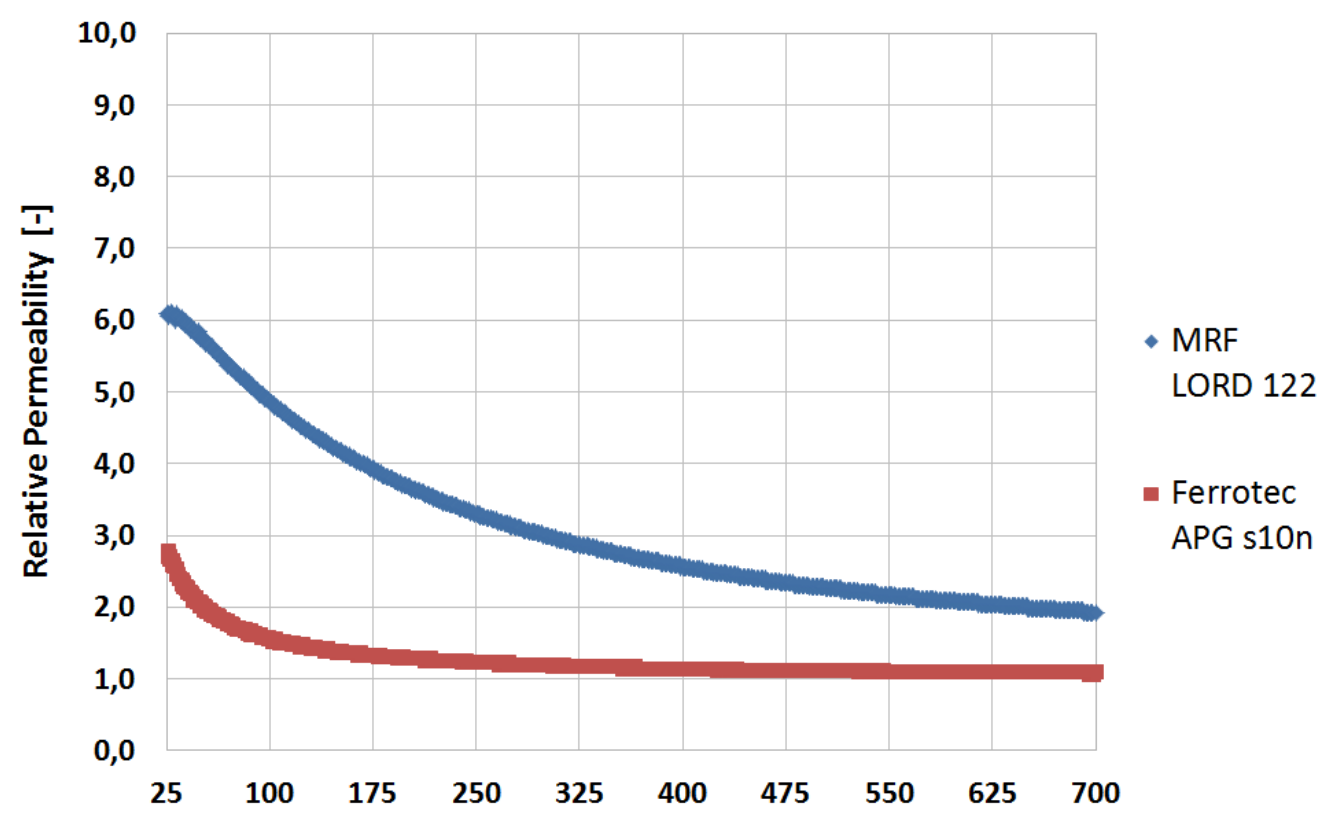

[H] Magnetic field strength $(\mathrm{kA} / \mathrm{m})$

Figure 3 Magnetic characterization of the magnetic fluids: relative permeability. 
143 Rheological analysis of magnetorheological fluid has been carried out following

144 Bingham model, Equation (1). Total shear stress of the fluid $(\tau)$ is the sum of yield

145 stress $\left(\tau_{0}\right)$, which is in function of magnetic field $(\mathrm{H})$, and the product of base viscosity

146 of the fluid $(\mathrm{K})$ and shear rate $(\dot{\gamma})$. Experimental values for MRF characterization are

147 shown in Figure 4:

$\tau=\tau_{0}(H)+K \cdot|\dot{\gamma}|$

148

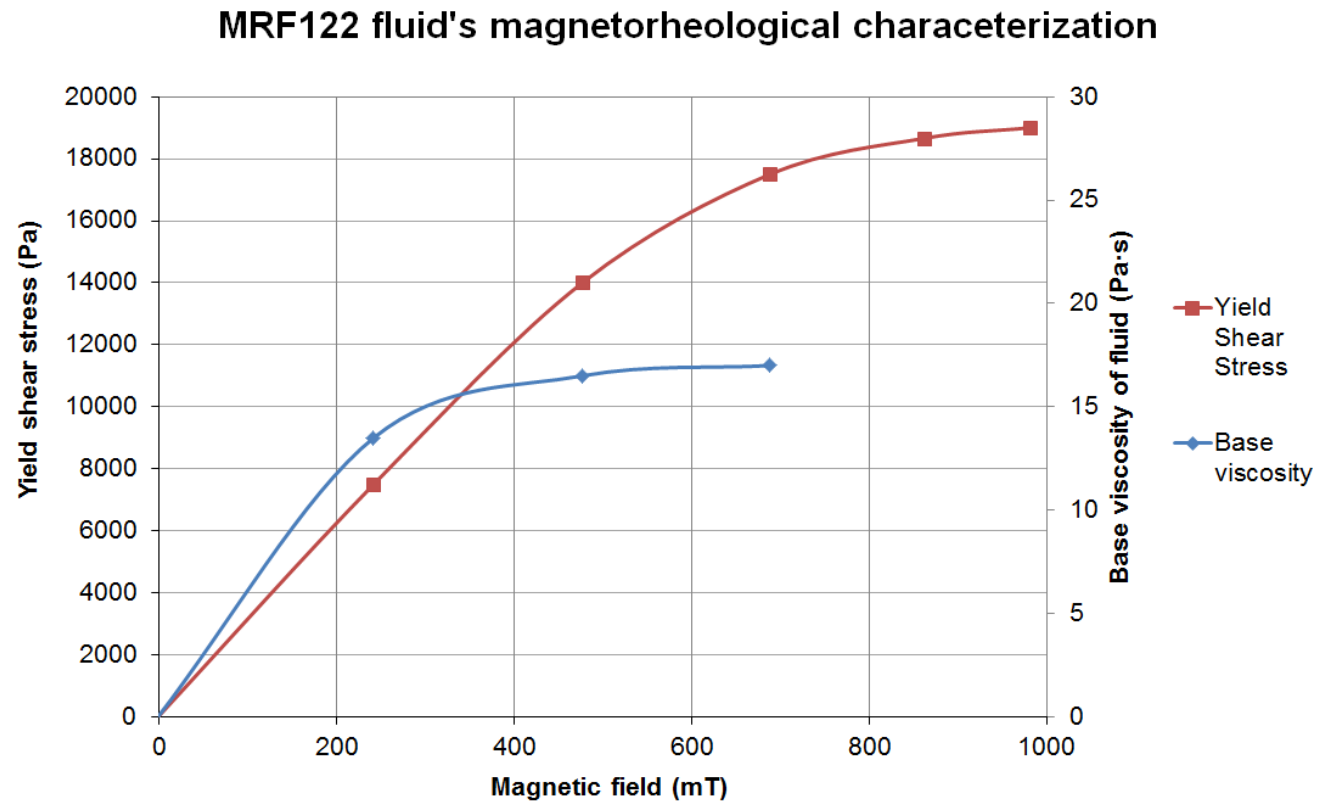

Figure 4 Rheological characterization of MRF: shear stress and base viscosity.

149 Ferrofluids rheology was characterized following tuneable Newtonian fluid (2),

150 where fluid dynamic viscosity $(\eta)$ it is in function of temperature (T) and applied 151 magnetic field $(\mathrm{H})$.

$\eta=\eta_{m}(H, T)$ 

magnetic field:

\section{Viscosity change with magnetic field and temperature}

Ferrofluid - Ferrotec APG s10n

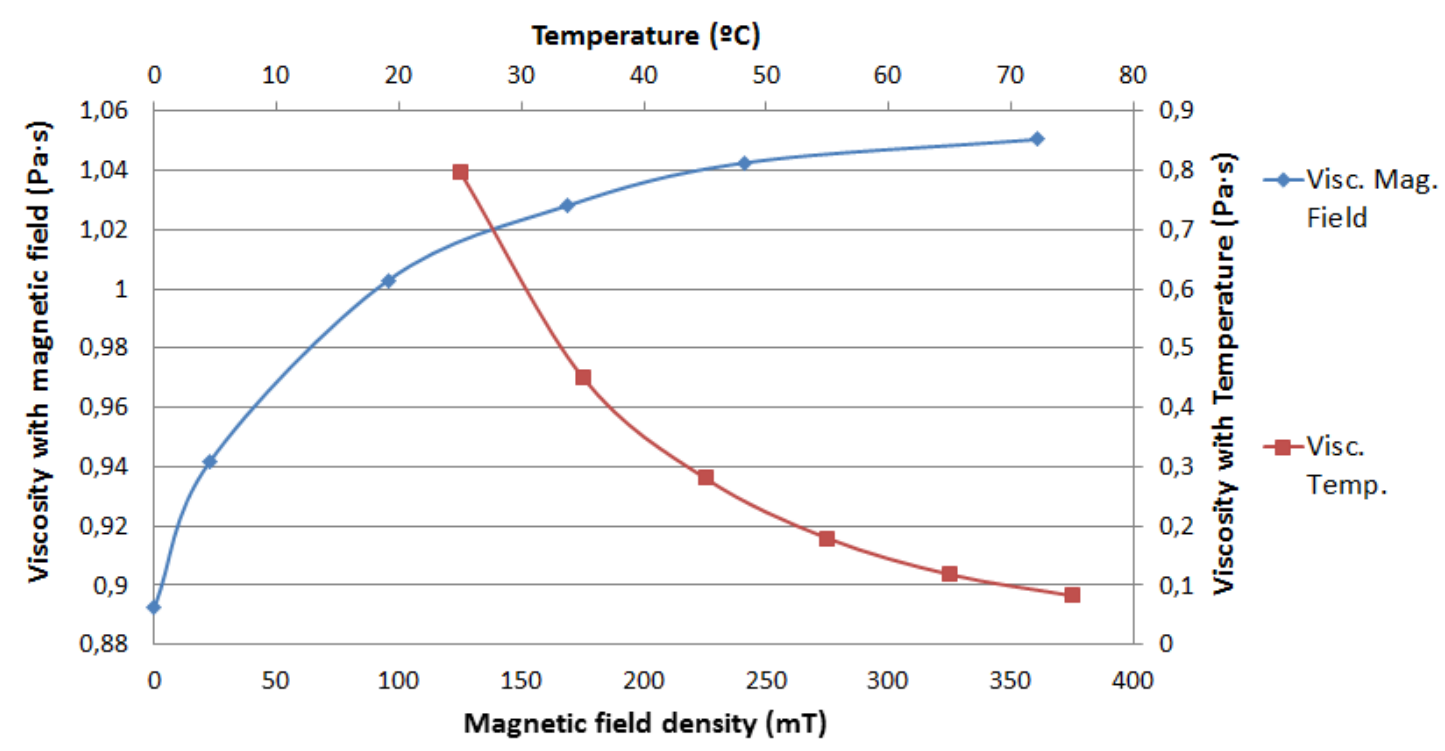

Figure 5 Rheological characterization of ferrofluid: viscosity and temperature.

A model of the magnetic fluid based seal was developed to support the prototype design process (see Section 4), and they were later validated with the experimental

159 evaluation (see Section 5). The model considers the magnetic field in the seal and the 160 pressure in the fluid.

161 Magnetic simulations were performed to determine the magnetic field strength and

162 flux density with the FEMM finite element software. Then, fluid pressure was simulated

163 based on the model presented by Park, Kim, Hahn and Lee, [11], solved by integration 
164 in in-house software. Those results are based on the experimental values of magnetic

165 fluids characterization, section 2.

\subsection{Design of seals with magnetic fluids}

167

The ring of magnetic fluids based seal, as presented in Figure 1 (part 2), is

168 manufactured by different groves and edges. In this section the shape of these ring

169 edges was discussed and designed. Four different designs were studied for the ring,

170 which are presented in Fig.6: a) plain seal, b) square rings, c) saw shape and d)

171 triangular shape. In all those cases the gap, overall geometry and magnet were the same,

172 so only the effect of rings shape was analysed.

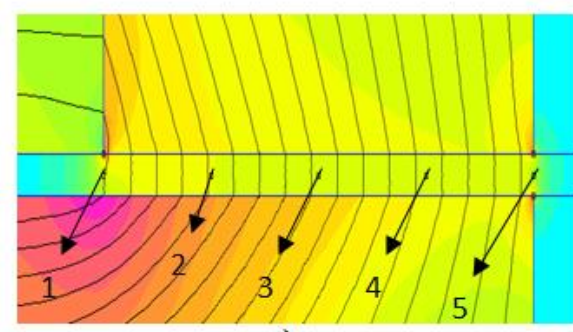

a)

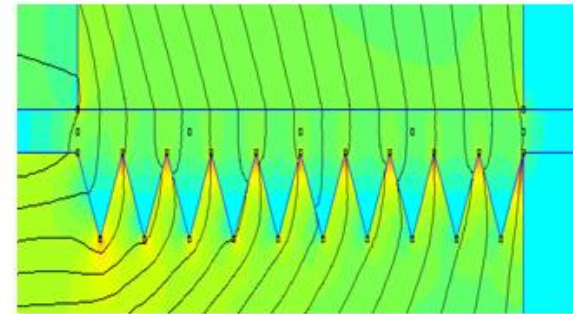

c)

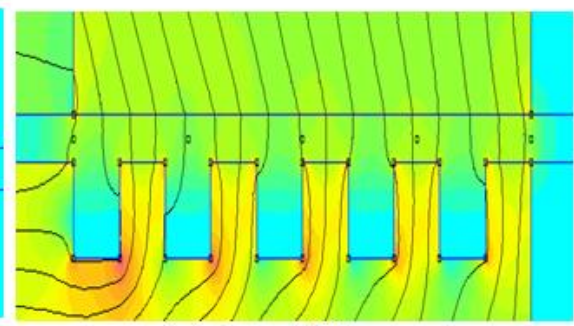

b)

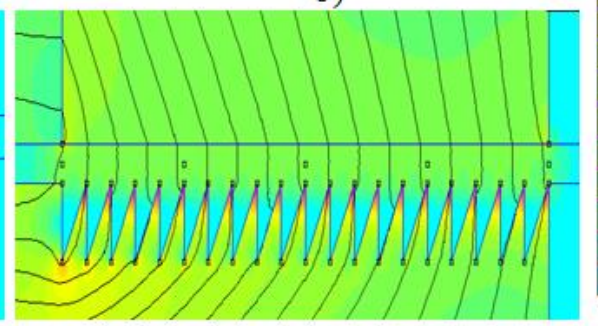

d)
$9.955 \mathrm{e}-001:>1.048 \mathrm{e}+000$ $9.431 \mathrm{e} .001: 9.955 \mathrm{e} .001$ $8.907 \mathrm{e} \cdot 001: 9.431 \mathrm{e}-001$ $8.383 \mathrm{e}-001: 8.907 \mathrm{e}-001$ $7.860 \mathrm{e}-001: 8.383 \mathrm{e}-001$ $7.336 \mathrm{e}-001: 7.860 \mathrm{e}-001$ $6.812 \mathrm{e}-001: 7.336 \mathrm{e}-001$ $6.288 \mathrm{e}-001: 6.812 \mathrm{e}-001$

$5.765 \mathrm{e}-001: 6.288 \mathrm{e}-001$ $5.241 \mathrm{e}-001: 5.765 \mathrm{e} .001$ $4.7178-001: 5.2418-001$ 4. $194 \mathrm{e}-001: 4.717 \mathrm{e}-001$ $3.670 \mathrm{e}-001: 4.194 \mathrm{e}-001$

$3.146 \mathrm{e}-001: 3.670 \mathrm{e}-001$

$2.622 \mathrm{e}-001: 3.146 \mathrm{e}-001$

$2.099 \mathrm{e}-001: 2.622 \mathrm{e}-001$

$1.575 \mathrm{e}-001: 2.099 \mathrm{e}-001$

$1.051 \mathrm{e}-001: 1.575 \mathrm{e} \cdot 001$

$5.275 \mathrm{e}-002: 1.051 \mathrm{e}-001$

$<.7678-004: 5.2758-002$

Density Plot: |B|, Tesla

Figure 6 Magnetic field distribution for different rings shape studied in the paper : a) plain seal, b) square rings, c) saw shape and d) triangular rings.

The magnetic flux density was simulated in the fluid for these four different shapes,

174 where the field is generated by a permanent magnet. The simulations were carried out

175 considering axis-symmetry assumption (cylindrical structure like shown in the section view of Figure 1), and magnetic model of the seal is depicted in Figure 7: 

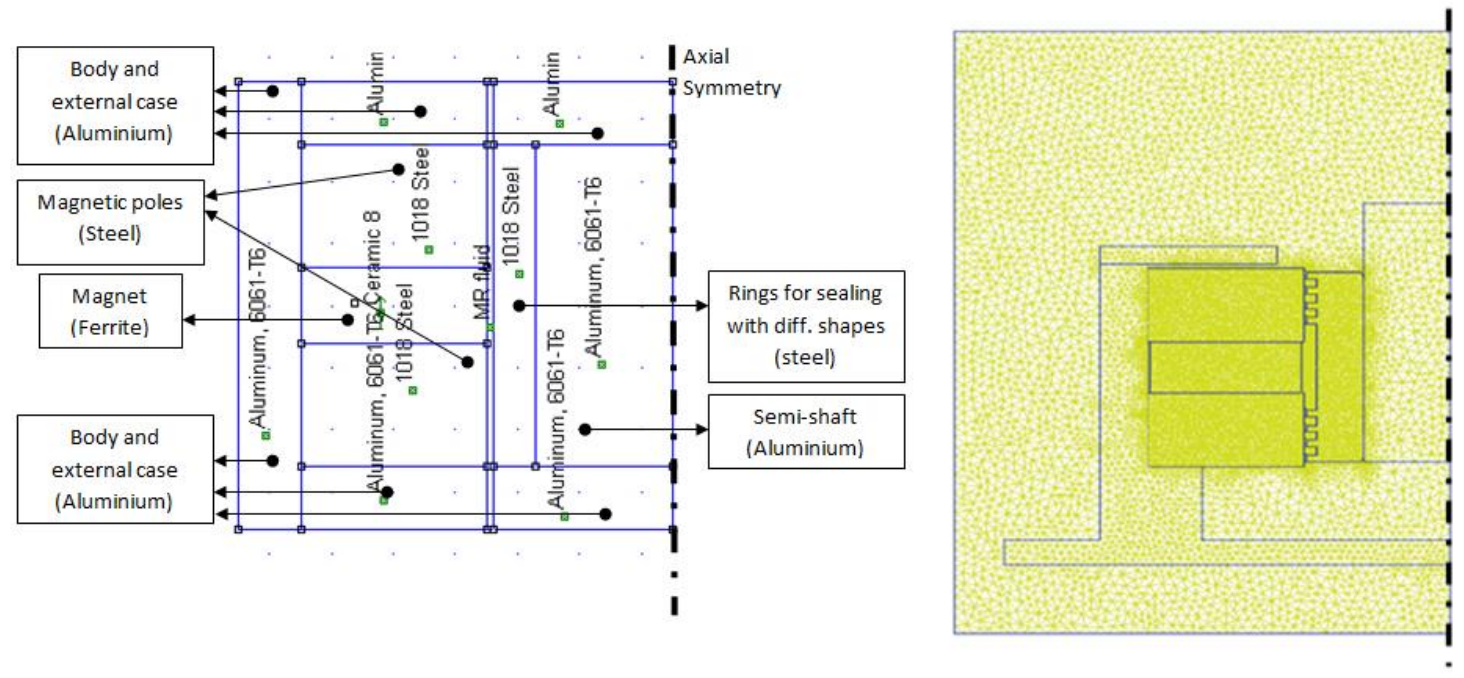

Figure 7 Magnetic fluid seal magnetic model with parts description and detail of mesh.

177 Magnetic field simulations were carried out with the open source software FEMM

178 (http://www.femm.info). The minimum, maximum and average values of the magnetic

179 field and the magnetization in the fluid for different rings shape (a, b, c and d), and in

180 five control points (shown in Figure 6-a) are summarized in Table 1.

Table 1 Magnetic flux density (B-Tesla) values in the fluid.

\begin{tabular}{|l|l|c|c|c|c|l|l|l|}
\cline { 2 - 9 } \multicolumn{1}{c|}{} & \multicolumn{9}{c|}{ Control points in the model } & \multicolumn{1}{c|}{} \\
\hline Shape & 1 & 2 & 3 & 4 & 5 & $\mathrm{~B}_{\min }$ & $\mathrm{B}_{\max }$ & $\mathrm{B}_{\text {ave }}$ \\
\hline Plain & 0.4167 & 0.4719 & 0.4661 & 0.4620 & 0.3443 & 0.3433 & 0.4760 & 0.4167 \\
\hline Square & 0.4481 & 0.3770 & 0.4641 & 0.5026 & 0.3832 & 0.3591 & 0.5105 & 0.4398 \\
\hline Saw & 0.4885 & 0.4206 & 0.4603 & 0.4127 & 0.3534 & 0.3534 & 0.4939 & 0.4236 \\
\hline Triang. & 0.4620 & 0.4508 & 0.4459 & 0.4424 & 0.3486 & 0.3486 & 0.4729 & 0.4107 \\
\hline
\end{tabular}

181 Considering the higher magnetic flux density achieved (from 0.359T to 0.510T),

182 square rings were selected for the development of a magnetic fluid seal prototype. 
184 The final step in the modelling of magnetic fluids seals was to determine the sealing capacity (pressure difference withstood by the rings) that they could achieve. In the case of MRF based seals, the sealing capacity is defined by the yield stress (function of

187 magnetic field), which was experimentally described in Section 2 by Equation (1) and 188 experimental results summarized in Figure 4.

189 For ferrofluids, the pressure achievable by each ring of the seal was determined 190 following Equation (4),[18].

$$
\begin{aligned}
& p_{m}=\max \left[\int_{H_{1}}^{H_{2}} \mu_{0} M d H\right] \\
& p_{m} \approx \max \left[\mu_{0} M_{S}\left(H_{2}-H_{1}\right)\right]
\end{aligned}
$$

191 Where $\left(\mathrm{p}_{\mathrm{m}}\right)$ is the pressure in the fluid due to the magnetic field, $\left(\mu_{0}\right)$ is the 192 permeability in the vacuum, $\left(\mathrm{M}_{\mathrm{s}}\right)$ the saturation magnetization of the fluid and $(\mathrm{H})$ the 193 magnetic field intensity, $\mathrm{H}_{1}$ and $\mathrm{H}_{2}$ are the values of the magnetic field intensity on both 194 free ferrofluid surfaces within one sealing stage.

In Equation (3), $\mathrm{M}$ is function of $\mathrm{H}$, as shown in Figure 8. If the variation of 196 magnetization with field is neglected at high fields within the bearing seal, and the 197 magnetization is put equal to saturation magnetization $\left(\mathrm{M}_{\mathrm{s}}\right)$, than one can use Equation 198 (4). The maximum pressure corresponds to the maximal difference of fields $\mathrm{H}_{1}$ and $\mathrm{H}_{2}$ 199 and is calculated imposing a certain volume of the ferrofluid ring and displacing this 200 volume along the shaft direction by small steps. the magnetic field simulation carried out in section 3.1. Finally, the sealing capacity is 
203 determined calculating the integral in Eq. (3) as presented graphically in Figure 8, and

204 finding its maximum for a given volume of the ferrofluid contained in one sealing stage:

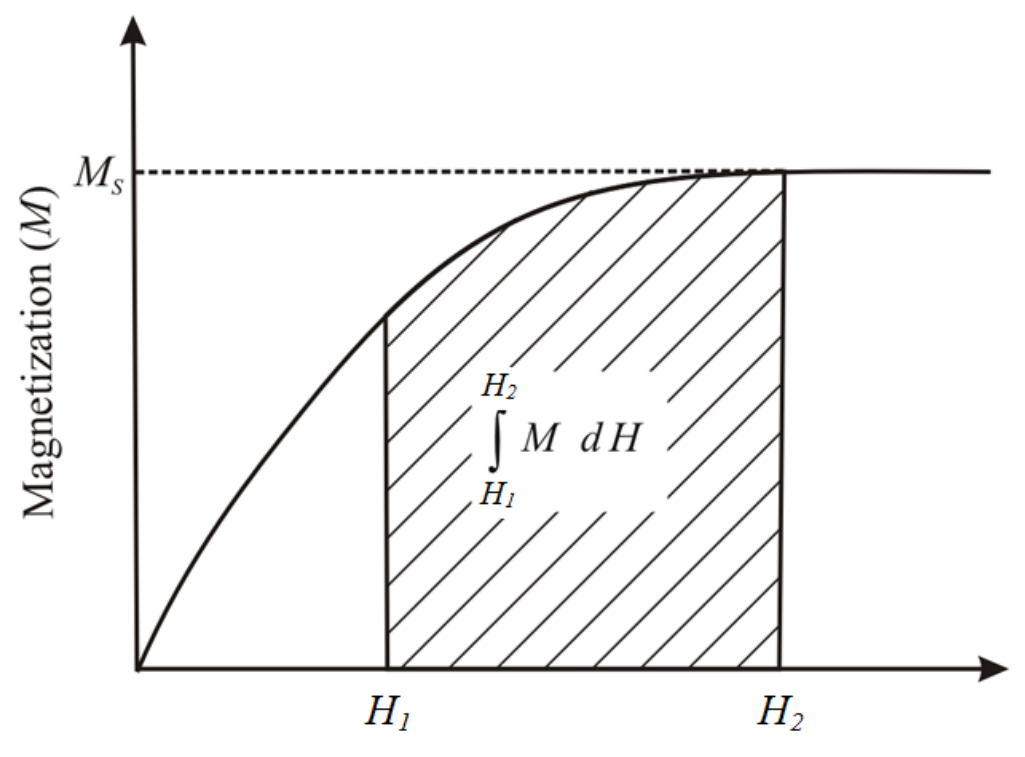

Magnetic field strength $(H)$

Figure 8 Fluid magnetization and magnetic field strength, pressure computation (Equation (3)).

The nature and therefore the response of MRF are different from ferrofluids so the

206 calculations were based on the yield stress in the rings and the average pressure achievable by the seal.

Once the yield stress was obtained (from magnetic simulations and fluids experimental analysis), the pressure in the ring was achieved with the computation of

210 Equation (5):

$$
F_{m}=2 \pi\left(R_{i} \int \tau_{0}\left(H_{i}\right) d z+R_{e} \int \tau_{0}\left(H_{e}\right) d z\right)
$$

211 Where $R_{i}$ and $R_{e}$ are the shaft radius and the internal radius of the magnetic poles; $H_{i}$

212 and $\mathrm{H}_{\mathrm{e}}$ - the magnetic field intensity on the shaft and magnetic pole surfaces. If the field

$213 \mathrm{H}$ does not change significantly across the gap of the seal $\left(\mathrm{H}_{\mathrm{i}} \approx \mathrm{H}_{\mathrm{e}} \approx \mathrm{H}\right)$, Equation (6) is

214 applied: 


$$
F_{m}=2 \pi\left(R_{i}+R_{e}\right) \int \tau_{0}(H) d z
$$

215 Finally, the fluid magnetic force $\left(F_{m}\right)$ was divided by the annular area $\left(A_{r}\right)$ of the ring

216 and gapto get the sealing pressure $\left(p_{m}\right)$, or sealing capacity, as presented in Equation (7).

$$
p_{m}=F_{m} / A_{r}
$$

\section{4. DESING OF SEAL PROTOTYPE AND TEST BENCH}

218 The experimental analysis was carried on a test bench (see Figure 9) where the 219 prototype of magnetic fluid seal was analysed under variable operating conditions 220 (rotational speed and pressurized air).

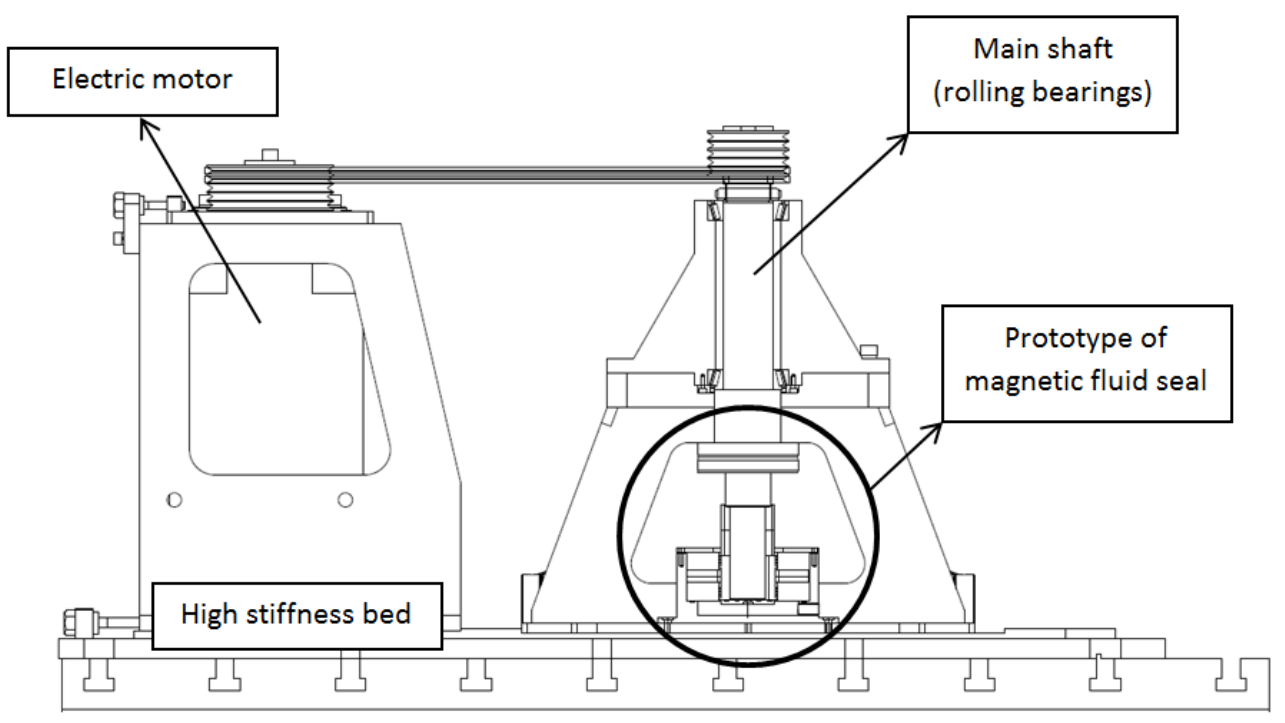

Figure 9 Test bench with the prototype of magnetic fluid based seal.

221 The magnetic fluid based seal prototype was located in the semi-shaft, which can 222 rotate up to $3000 \mathrm{rpm}$ with a run-out below $5 \mu \mathrm{m}$. The pressurization of the rings, tested 223 with an air inlet in the body, was evaluated in function of the rotational speed. 
224 Based on the results from magnetic calculations, a prototype of magnetic fluid seal 225 was designed. This prototype is analysed in the test bench presented in Figure 9, 226 assembled in the area marked with a circle. In Figure 10 a section view of the prototype 227 with main dimensions is presented.

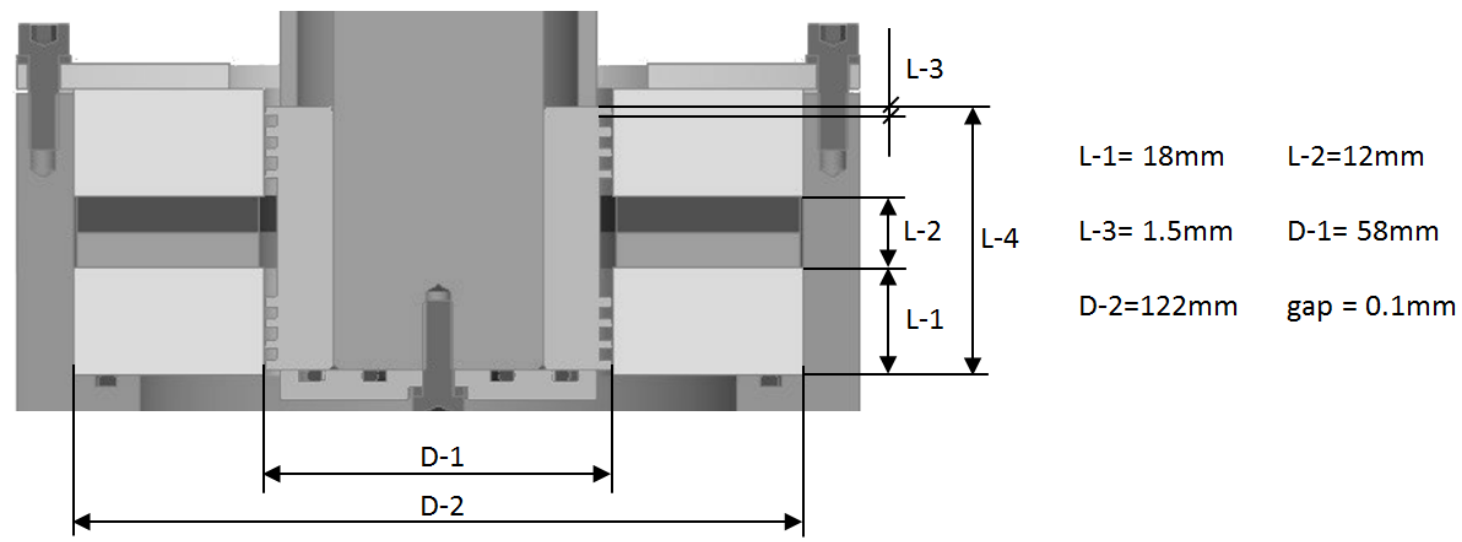

Figure 10 Magnetic fluids sealing, main dimensions

228 The magnetic field was created with a strontium ferrite permanent magnet located in 229 the sealing body and having an axial polarization $(120 \mathrm{~mm}$ external diameter, $60 \mathrm{~mm}$ 230 internal diameter and $12 \mathrm{~mm}$ thickness). The average magnetic field strength of the 231 magnet (given by manufacturer) was around $260 \mathrm{kA} / \mathrm{m}$, when flux density achieved is 232 around $0.4 \mathrm{~T}$. This magnetic field was guided with two annular poles towards the rings 233 of the sealing, 8 rings in this case as shown in Figure 10. The magnetic field in the rings 234 and a photo of a disassembled seal are shown in Figure 11. 


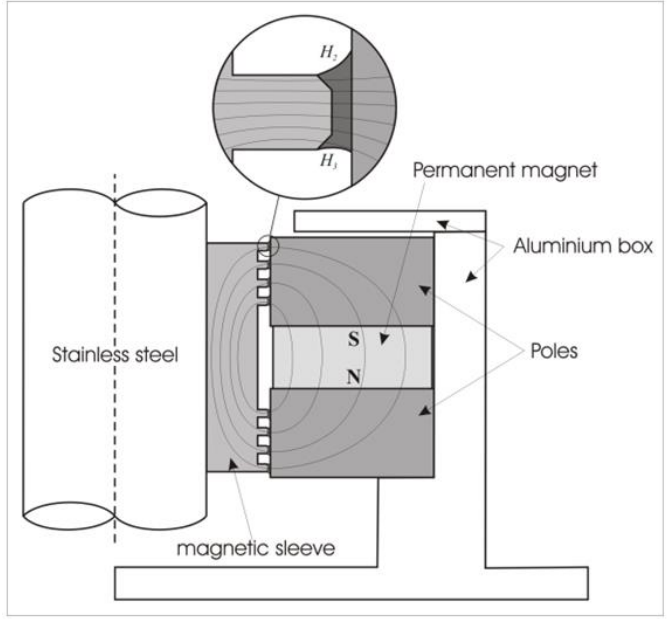

(a)

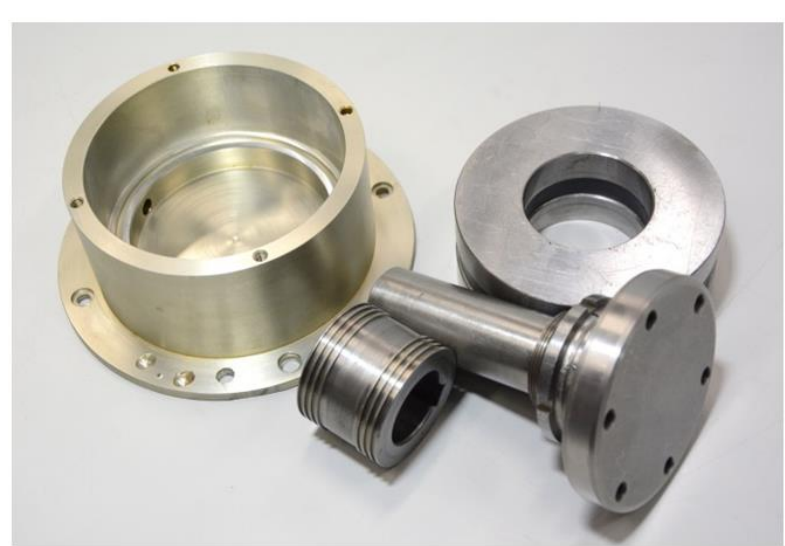

(b)

Figure 11 Magnetic fluids sealing, working principle (a) and manufactured set-up (b)

\section{RESULTS AND DISCUSSION}

The experimental tests to analyse the behaviour of magnetic fluids based seals are presented in this section. The section is structured in three parts: Analysis of the friction torque, sealing capacity of MRF and sealing capacity of ferrofluids.

\subsection{Friction torque analyse}

Friction torque was evaluated for two different magnetic fluids, FERROTEC APG s10n and LORD MRF122. In addition, two other magnetic fluids were tested: a dilution of $30 \%$ and $50 \%$ of MRF 122 . Finally, a lubricant oil fluid (viscosity ISO-VG 46) and

244 the torque without any fluid were also tested to determine friction of the kinematic 245 chain. Results are shown in Figure 12. The friction torque with MRF fluids, even under 246 diluted concentration, is very high, between 2 and $8 \mathrm{~N} \cdot \mathrm{m}$ at $100 \mathrm{rpm}$, too large to be used as sealing for spindles of machine tools. The torque with ferrofluid in the seal was 
248 slightly higher than base friction, around $0.25 \mathrm{~N} \cdot \mathrm{m}$, at the same rotation speed of the

249 shaft eligible to be used in machine tool applications.

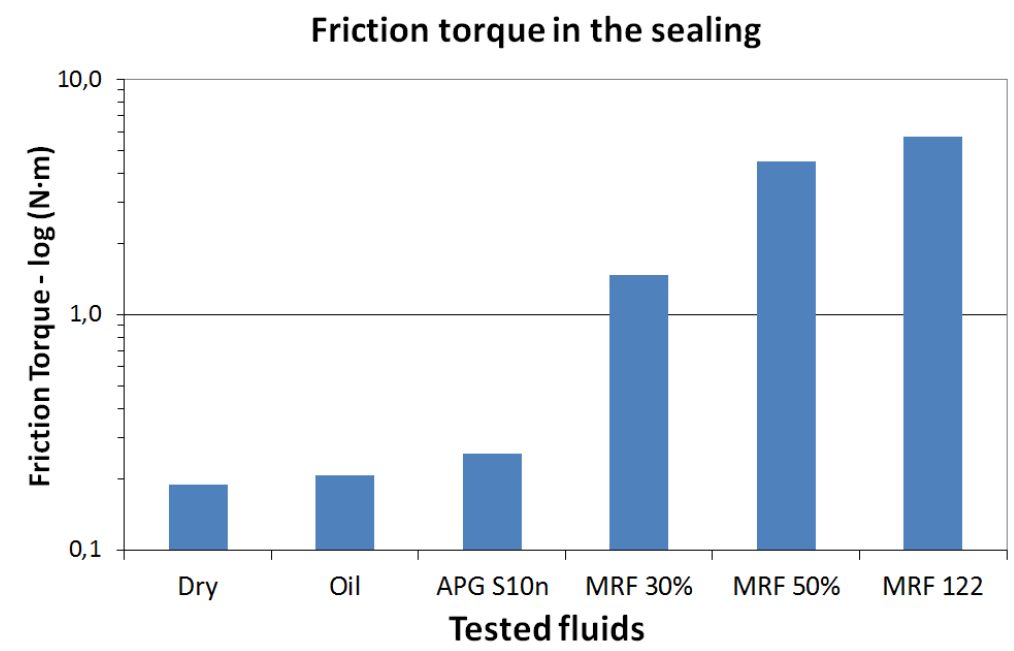

Figure 12 Friction torque in the sealing with different magnetic fluids at 100rpm.

251 Tests were carried out to determine the sealing capacity of the system, evaluated as 252 the pressure difference that it can sustain. The experimental procedure was the same for 253 both magnetic fluids, MRF and ferrofluids (section 5.3), and it was the following the

254 scheme shown in the Figure 13: the sealing body was filled gradually with compressed 255 air, controlling the inlet air with a flow valve. The flow rate and pressure were measured 256 with a flowmeter and a pressure gauge, respectively. This set-up was used for the 257 experimental validation of the magnetic seals, and the characterization of sealing 258 capacity of the tested magnetic fluids. 


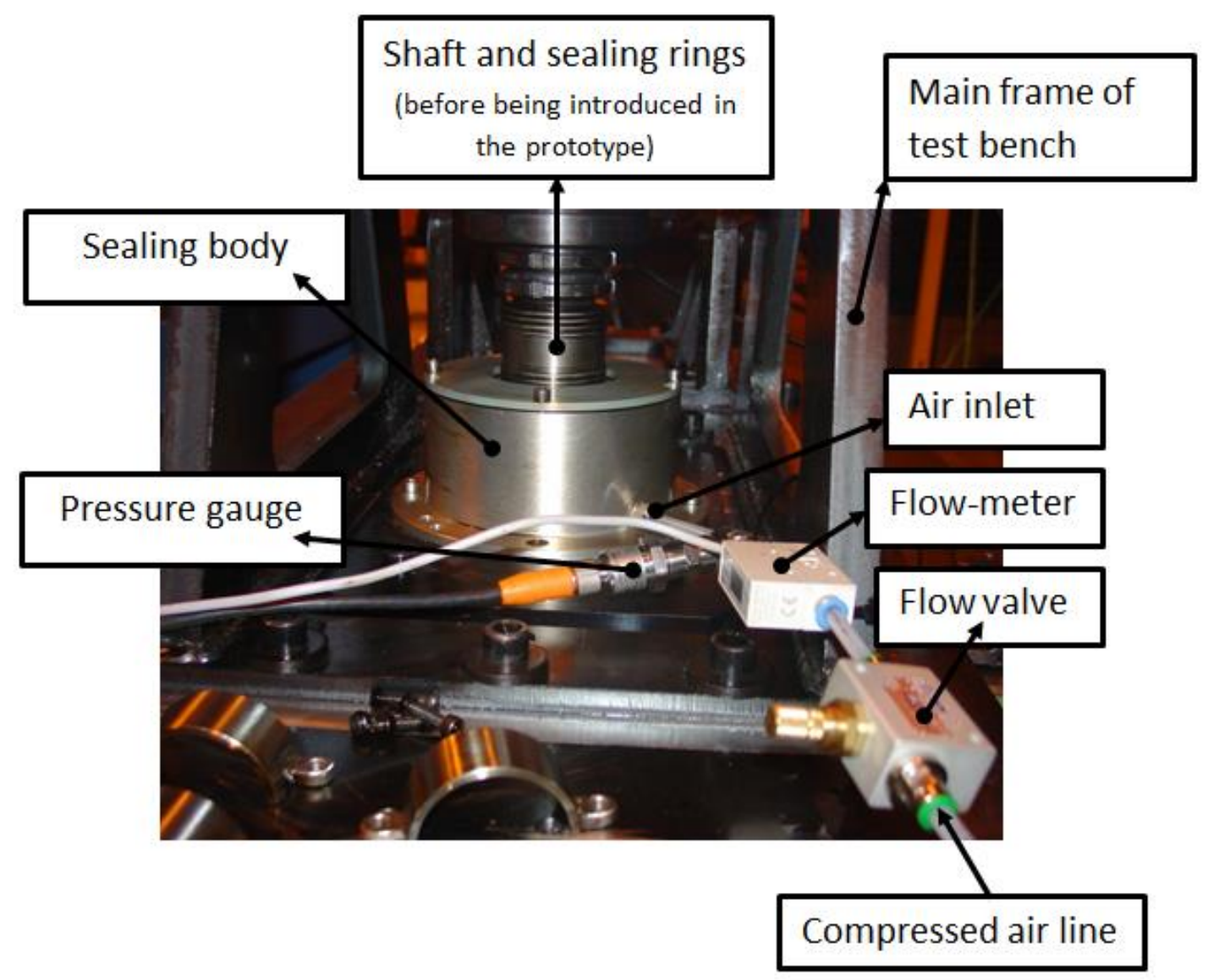

Figure 13 Friction torque in the sealing with different magnetic fluids.

260 Once the maximum pressure was reached two behaviours were shown: In the case of

261 MRF the pressure stayed constant, and with the ferrofluids the magnetic seals broke

262 (falling down the pressure) and the flowrate increased instantaneously. After a recovery

263 time the seal was formed again and the air pressure increased again till the previous

264 limit (maximum pressure) periodically.

265 The prototype was composed of eight sealing rings, therefore the sealing capacity of

266 each ring, evaluated with the integration of equation (4) for ferrofluids and Equation

267 Erreur ! Source du renvoi introuvable. and Erreur ! Source du renvoi introuvable.

268 for MRF, it was multiplied by eight. The results from model and the experimental tests

269 are summarized and compared in Table 2: 


\begin{tabular}{|c|c|c|c|c|c|}
\hline \multirow{2}{*}{\multicolumn{2}{|c|}{ Sealing capacity $(\boldsymbol{k P a})$}} & \multicolumn{2}{|c|}{ MRF 122 (dilution 30\%) } & \multicolumn{2}{|c|}{ MRF 122} \\
\hline & & \multirow{2}{*}{$\begin{array}{c}\text { per ring } \\
12.36\end{array}$} & \multirow{2}{*}{$\begin{array}{c}\text { Seal } \\
98.88\end{array}$} & \multirow{2}{*}{$\begin{array}{c}\text { per ring } \\
41.2 \\
\end{array}$} & \multirow{2}{*}{\begin{tabular}{|l|} 
Seal \\
336.8
\end{tabular}} \\
\hline Calculated & Min & & & & \\
\hline capacity & Max & 15.75 & 126.0 & 52.5 & 420.0 \\
\hline $\begin{array}{l}\text { Experimental value } \\
\text { seal (shaft at rest) }\end{array}$ & $n$ the & ---- & 130.0 & ---- & 320.0 \\
\hline
\end{tabular}

270 In the case of MRF the pressure for each ring goes from $41.2 \mathrm{kPa}$ to $52.5 \mathrm{kPa}$ in

271 function of the magnetic field in the fluid, which as shown in Figure 6, is not constant

272 over the ring. For the case of $30 \%$ dilution, assuming a proportional reduction of yield

273 stress, and therefore the sealing capacity, the theoretical values go from $12.36 \mathrm{kPa}$ to

$27415.75 \mathrm{kPa}$. Summarizing, the theoretical sealing capacity of MRF for all system with

275 eight rings was: $336.8 \mathrm{~Pa}$ (3.3bar) to $420 \mathrm{kPa}$ (4.2bar), and for $30 \%$ diluted MRF:

$276 \quad 98.9 \mathrm{kPa}(0.99 \mathrm{bar})$ and $126 \mathrm{kPa}(1.26 \mathrm{bar})$.

Sealing capacity of MRF

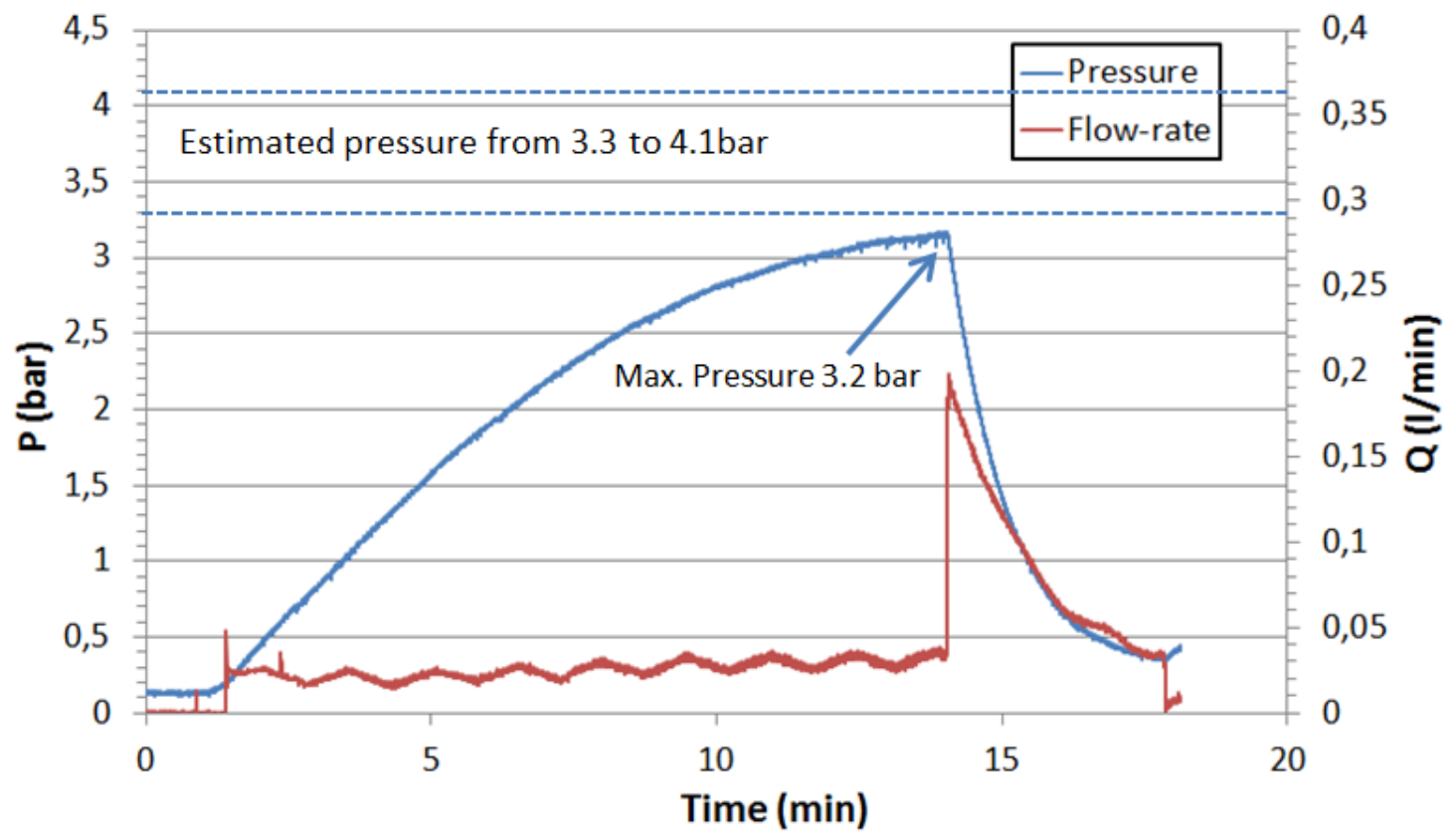

Figure 14 Seal capacity of the system with MRF. 
278 slightly lower than the expected values, which go from 3.3 to 4.1 bar following the 279 simulations and calculations described above. Due to the high friction torque of MRF, a 280 diluted fluid at $30 \%$ was analysed, where the results are shown in Figure 15. In this case 281 the experimental value matches with expected pressure, from 0.99 to $0.126 \mathrm{bar}$.

\section{Sealing capacity of MRF, $\mathbf{3 0} \%$}

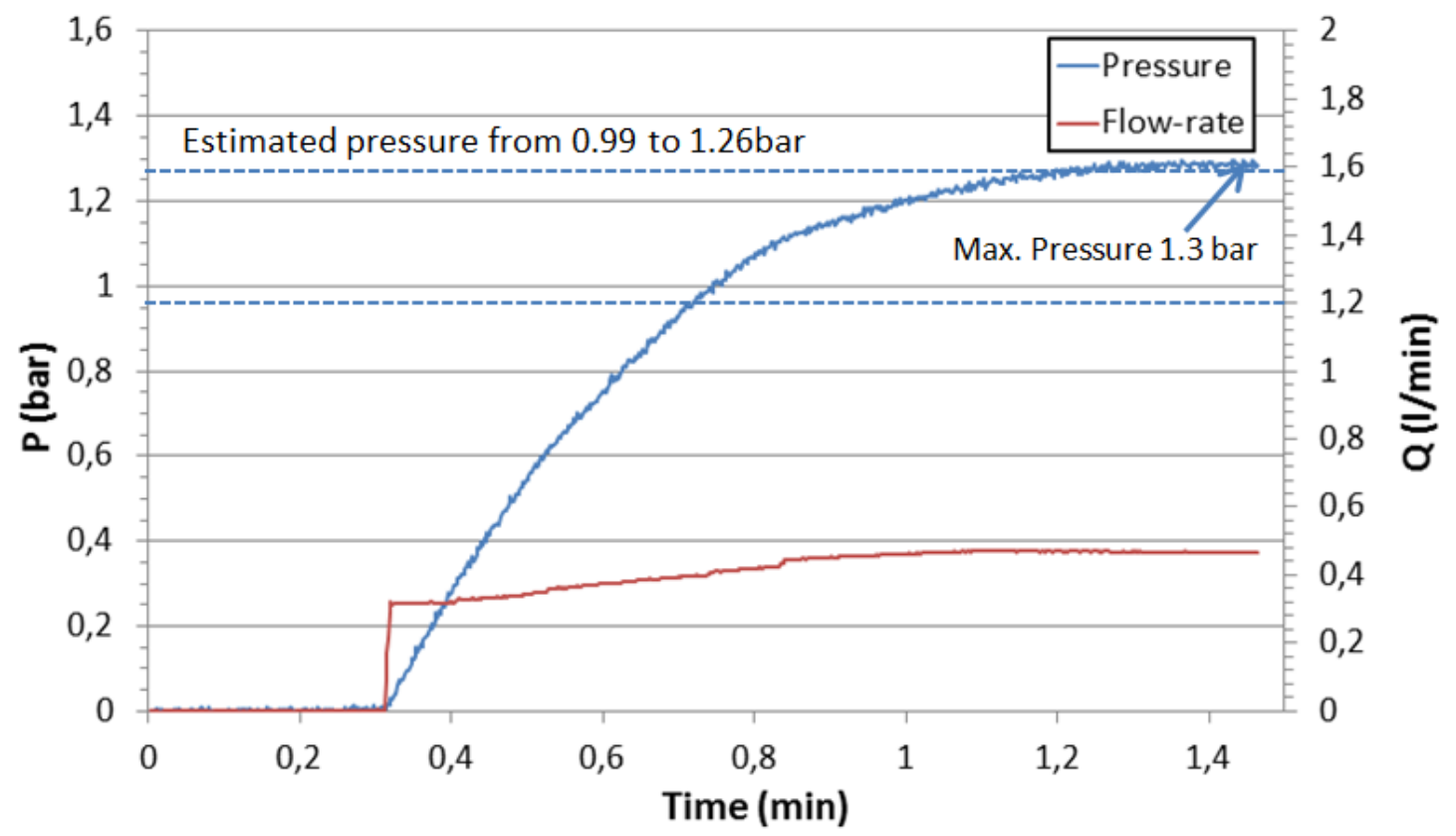

Figure 15 Seal capacity of the rings with MRF at 30\% dilution.

Those results were obtained at rest because the pressure in the rings was the same for

283 analysed rotational speed, up to 100rpm. Rupture and recovery pressure were not 284 detected as in ferrofluid based seals, (see section 5.3).

285 MRF based seals have high sealing capacity, but the friction torque presented in the 286 system is not compatible with machine tool spindle application. 
In Figure 16 the pressure value estimated in each one of the ring filled with

289 ferrofluids is shown, where as calculated the average pressure value was around $9 \mathrm{kPa}$,

290 which means a total pressure capacity (by eight), around $72 \mathrm{kPa}(0.72 \mathrm{bar}$ ) in the

291 prototype. The summary of results is presented in Table 3:

Table 3 Ferrofluid based seal, sealing capacity $(\mathrm{Pa})$.

292

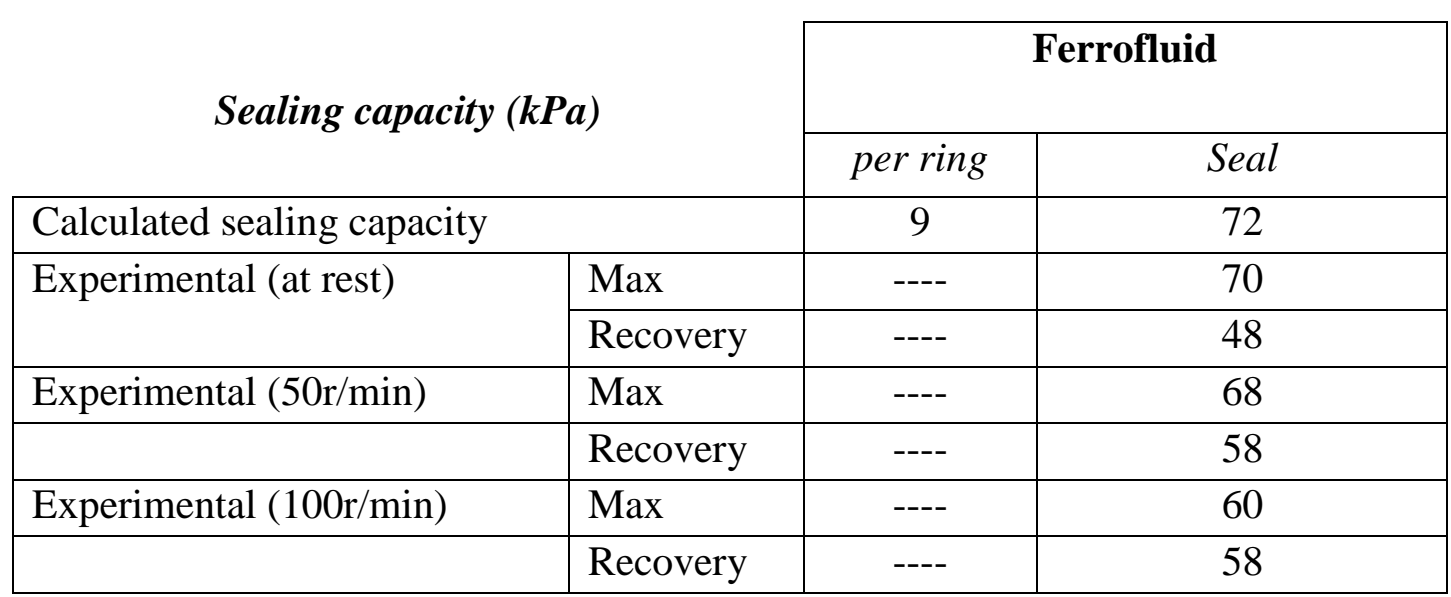

293 Recovery pressure, as shown in Figure 17, was the pressure where the magnetic seals

294 (after rupture at maximum pressure) got again pressurization, recovering sealing

295 capacity. These values are a very good pressurization capacity to be used in machine

296 tool's spindles, which together with the low friction torque in the shaft it could be

297 considered as a good candidate for industrial application. 


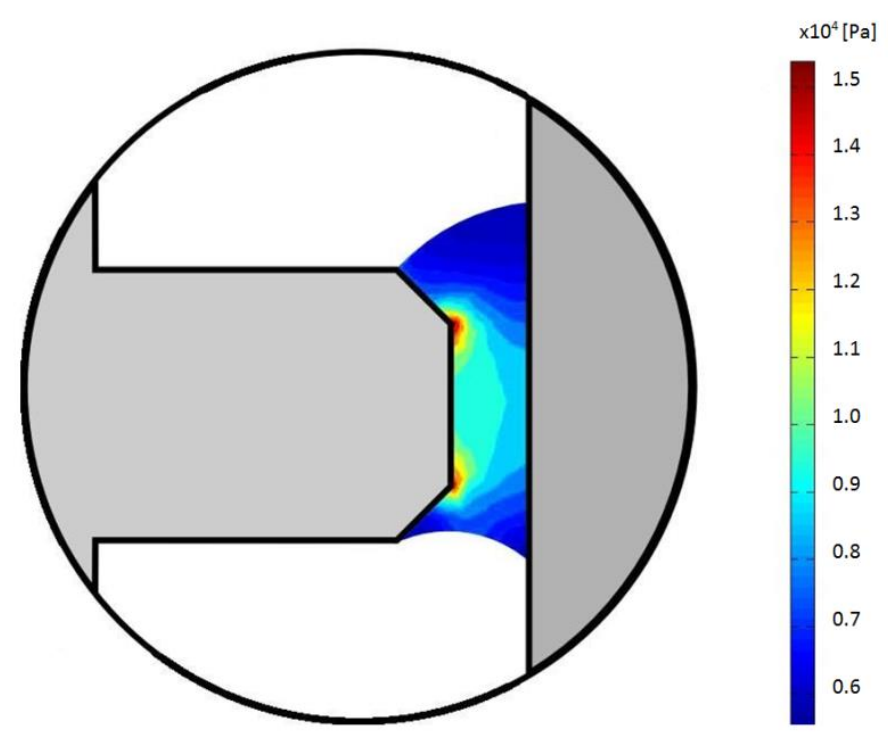

Figure 16 Sealing capacity of each ring with ferrofluid FERROTEC APG s10n.

$2990 \mathrm{rpm}, 50 \mathrm{rpm}$ and 100rpm respectively are shown.

\section{Sealing capacity at Orpm}

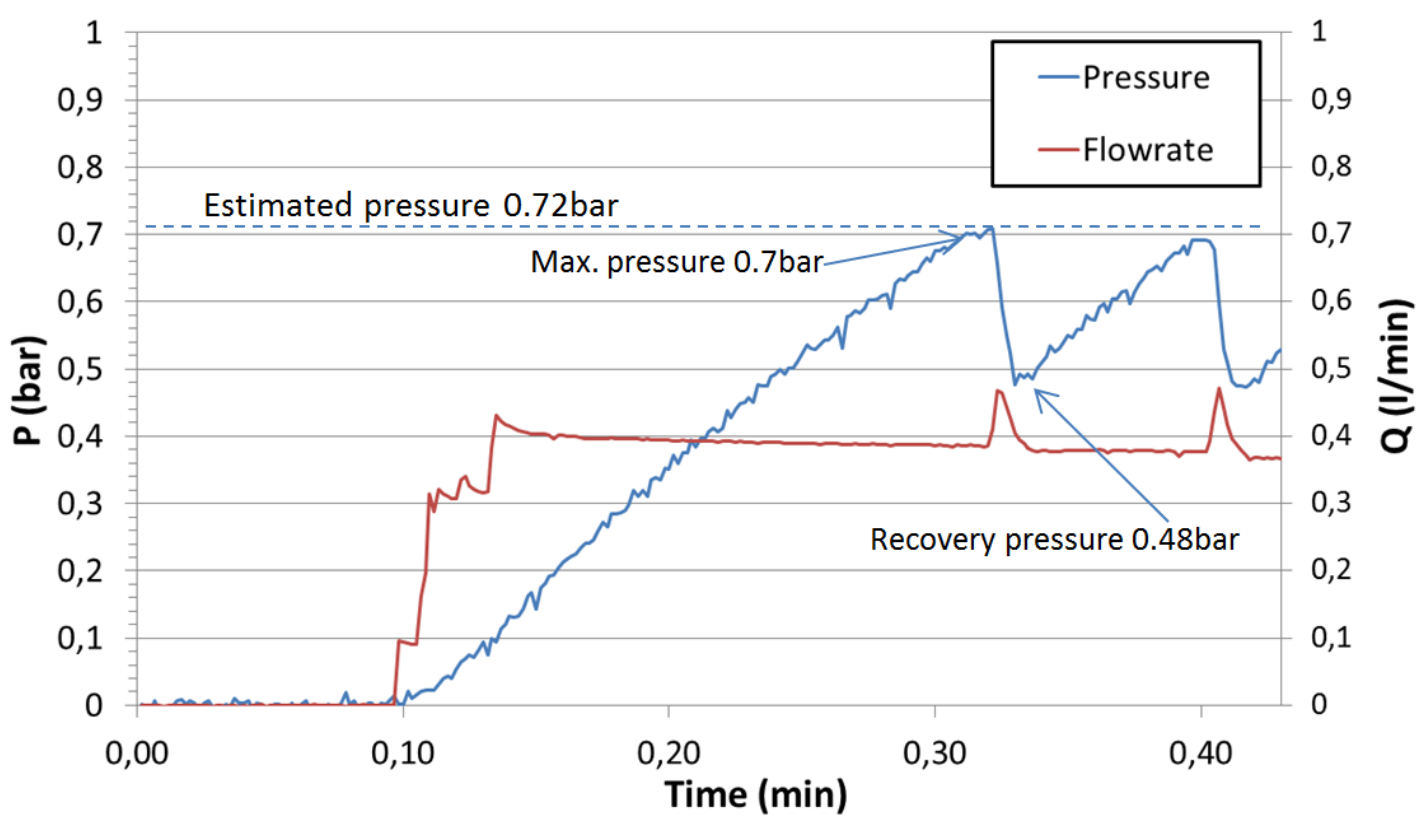

Figure 17 Sealing capacity at rest with FERROTEC APG s10n 


\section{Sealing capacity at 50rpm}

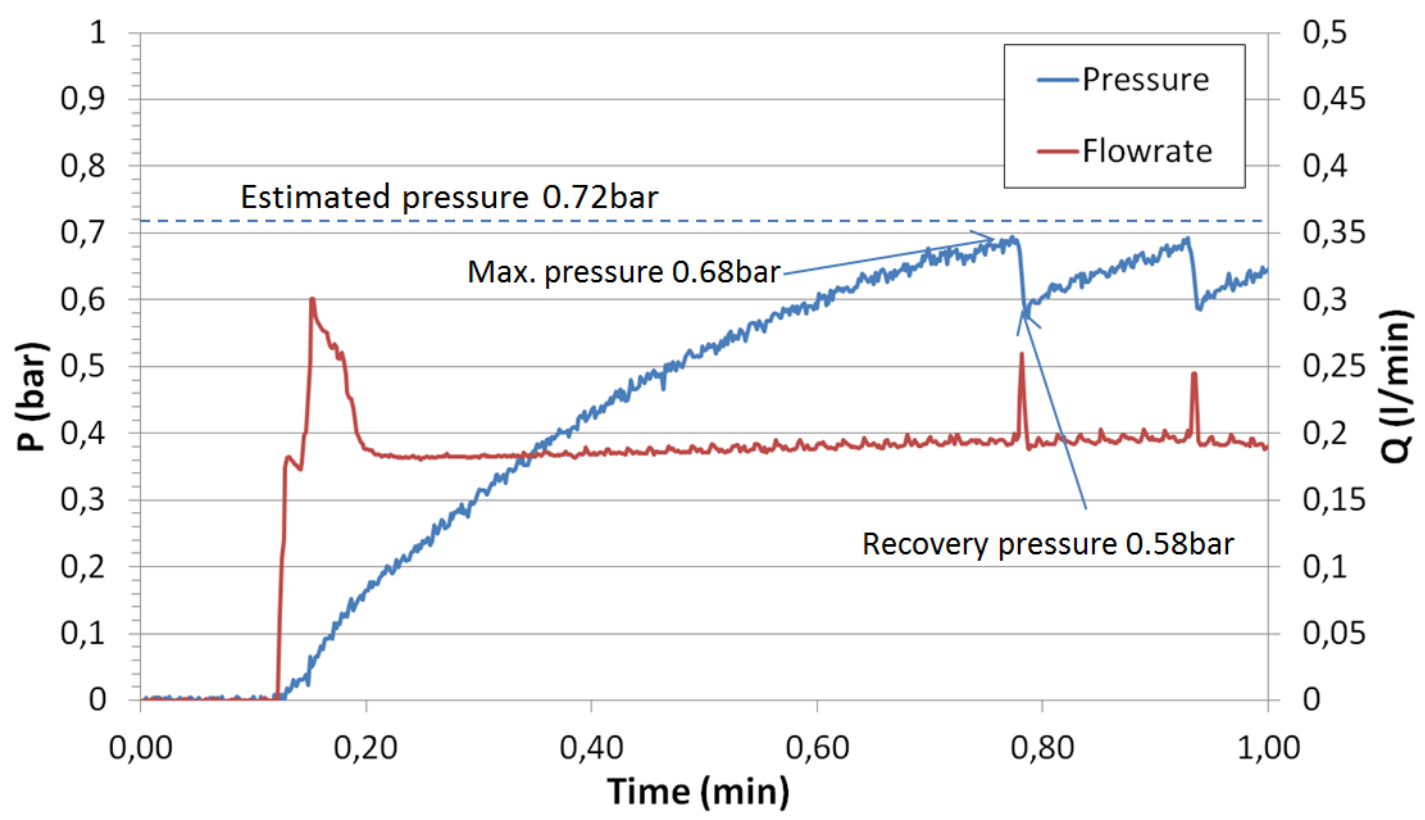

Figure 18 Sealing capacity at rest with FERROTEC APG s10n

\section{Sealing capacity at 100rpm}

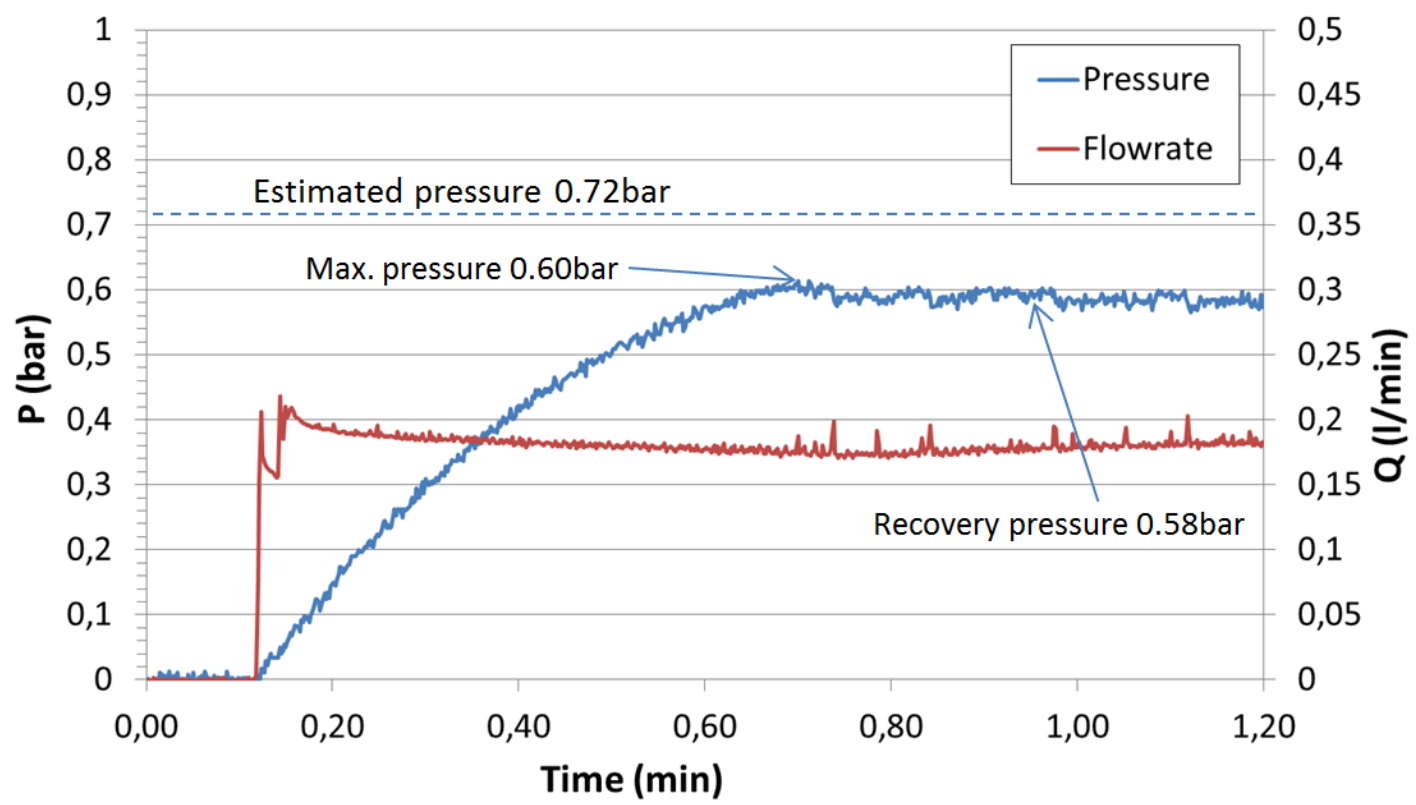

Figure 19 Sealing capacity measured in the test bench with FERROTEC APG s10n. 
300 As shown in Figure 17, the maximum pressure of the sealing matched quite well 301 with the estimated value, around 72000Pa. When the shaft was rotating (see Figure 18),

302 the difference between maximum pressure and recovery pressure was reduced, and at 303 100r/min (see Figure 19), both pressures were almost equal, converging at a value 304 around 0.6bar. Above this rotational speed it was not noted variations in the results.

\section{CONCLUSIONS}

306 The use of magnetic fluids as active elements in seals was analysed in this research 307 work. A close to industrial application prototype has been developed, and the validity of 308 the simulation models and the final performance of the systems were demonstrated 309 experimentally.

- Two magnetic fluids (a ferrofluid and a MRF) were experimentally analysed, obtaining deeper information about their behaviour than that offered by the manufacturers. Such a detailed experimental characterization is highly recommended for any studies in the field of magnetic fluids.

- MRF and ferrofluid based seal models were developed, simulating the magnetic field and the sealing capacity measured in pressure per ring.

- The seal based on MRF showed very good sealing performance (over 3 bar) but with an excessive friction torque $(8 \mathrm{Nm})$. Even diluted at $30 \%$, sealing was still good but the torque was too high for machine tool applications.

- The seal based on ferrofluids demonstrated a good enough sealing capacity (0.9bar) and with a friction torque slightly higher than without the seal.

- The seal based on ferrofluids showed thus true potential for industrialization in machine tool spindles. 


\section{REFERENCES}

[1] A. H. Slocum, Precision Machine Design. Englewood Cliffs, N.J.: Society of Manufacturing Engineering (SME), 1992.

[2] R. Bassani y B. Piccigallo, Hydrostatic Lubrication. Pisa University, Italy: Elsevier, 1992.

[3] H. K. Müller y B. S. Nau, Fluid Sealing Technology: Principles and Applications, 1998. ${ }^{a}$ ed. CRC Press, 1998.

[4] J. M. Vance, Rotordynamics of Turbomachinery. Wiley, 1988.

[5] T. Hirano, Z. Guo, y R. G. Kirk, «Application of Computational Fluid Dynamics Analysis for Rotating Machinery-Part II: Labyrinth Seal Analysis», J. Eng. Gas Turbines Power, vol. 127, n. ${ }^{\circ}$ 4, pp. 820-826, sep. 2005.

[6] X. Yu, S. He, y R. . Cai, «Frictional characteristics of mechanical seals with a laser-textured seal face», Journal of Materials Processing Technology, vol. 129, n. ${ }^{\circ} 1-3$, pp. 463-466, oct. 2002.

[7] X. Wang y A. Yamaguchi, «Characteristics of hydrostatic bearing/seal parts for water hydraulic pumps and motors. Part 1: Experiment and theory», Tribology International, vol. 35, n. ${ }^{\circ}$, pp. 425-433, jul. 2002.

[8] S. Odenbach, Magnetoviscous Effects in Ferrofluids. Springer, 2002.

[9] J. D. Carlson, D. M. Catanzarite, y K. A. St. Clair, «COMMERCIAL MAGNETORHEOLOGICAL FLUID DEVICES», International Journal of Modern Physics B, vol. 10, n. $^{\circ} 23-24$, pp. 2857-2865, oct. 1996.

[10] J. A. Walowit y O. Pinkus, «Analysis of Magnetic-Fluid Seals», A $S L E$ Transactions, vol. 24, n. ${ }^{\circ}$, pp. 533-541, ene. 1981.

[11] G.-S. Park, D.-H. Kim, S.-Y. Hahn, y K.-S. Lee, «Numerical algorithm for analyzing the magnetic fluid seals», IEEE Transactions on Magnetics, vol. 30, n. ${ }^{\circ}$ 5, pp. 3351-3354, 1994.

[12] J. Zou, X. Li, Y. Lu, y J. Hu, «Numerical analysis on the action of centrifuge force in magnetic fluid rotating shaft seals», Journal of Magnetism and Magnetic Materials, vol. 252, pp. 321-323, nov. 2002.

[13] Z. Meng, Z. Jibin, y H. Jianhui, «An analysis on the magnetic fluid seal capacity», Journal of Magnetism and Magnetic Materials, vol. 303, n. ${ }^{\circ}$ 2, pp. e428-e431, ago. 2006.

[14] O. Lavrova, G. Matthies, T. Mitkova, V. Polevikov, y L. Tobiska, «Numerical treatment of free surface problems in ferrohydrodynamics», J. Phys.: Condens. Matter, vol. 18, n. ${ }^{\circ}$ 38, p. S2657, sep. 2006. 
[15] P. Kuzhir, «Free boundary of lubricant film in ferrofluid journal bearings», Tribology International, vol. 41, n. ${ }^{\circ}$, pp. 256-268, abr. 2008.

361

362

363

364

365

366

367

368

369

370

[16] R. Ravaud, G. Lemarquand, y V. Lemarquand, «Magnetic pressure and shape of ferrofluid seals in cylindrical structures», Journal of Applied Physics, vol. 106, n. ${ }^{\circ}$ 3, pp. 034911-034911-9, ago. 2009.

[17] V. R. Iyengar, A. A. Alexandridis, S. C. Tung, y D. S. Rule, «Wear Testing of Seals in Magneto-Rheological Fluids@», Tribology Transactions, vol. 47, n. ${ }^{\circ} 1$, pp. 23-28, 2004.

[18] W. Horak y M. Szczęch, «Experimental and numerical determination of the static critical pressure in ferrofluid seals», J. Phys.: Conf. Ser., vol. 412, n. ${ }^{\circ}$ 1, p. 012055 , feb. 2013. 